\title{
HONORED GUEST'S ADDRESS
}

\section{A PRACTICAL AFFAIR}

Kenneth M. Taylor, MD, FRCS, FRCSE, FESC, FETCS, FSA want to begin by thanking the Association and your president for this tremendous honor. I received Dr Loop's invitation in December 1996. Since then I have looked forward to this meeting with considerable anticipation and not a little trepidation.

There is a particular significance to my being here today. It was 21 years ago exactly-1977 in Torontothat I first attended a meeting of The American Association for Thoracic Surgery (AATS) and gave a presentation. That was my first visit to North America with my wife and our son and daughter (then aged 5 and 2). Immediately after the AATS meeting we drove to Cleveland, Ohio, for what was to be the first of many visits with Dr Loop and his colleagues at The Cleveland Clinic. That happy association has spanned 21 years.

Where do I begin? The logical place to start is at the beginning, with the title of this lecture: "A Practical Affair." These are the words of John Heysham Gibbon, $\mathrm{Jr}$, the man who developed and first used a heart-lung machine successfully in clinical cardiac surgery in 1953. His words were recorded 5 years earlier: "Some day the heart-lung machine will become a practical affair." That successful operation on May 6, 1953, exactly 45 years ago tomorrow, opened the doors to a new era in the treatment of heart disease. It is salutary to note in Ada Romaine-Davis's book on John Gibbon and his heart-lung machine that preoperative cardiologic diagnosis for the 18-year-old patient was less than precise. The operation note section on preoperative

BHF Professor of Cardiac Surgery at Hammersmith Hospital, Deputy Head, National Heart and Lung Institute, Imperial College School of Medicine, and Chief of Service, Cardiothoracic Surgery, Hammersmith Hospital, London, United Kingdom.

Read at the Seventy-eighth Annual Meeting of The American Association for Thoracic Surgery, Boston, Mass, May 3-6, 1998.

Received for publication Dec 1, 1998; revisions requested Dec 1, 1998; revisions received May 17, 1999; accepted for publication May 18, 1999.

Address for reprints: Kenneth M. Taylor, MD, FRCS, FRCSE, Cardiothoracic Surgical Unit, Hammersmith Hospital, Imperial College School of Medicine, London W12 0NN, United Kingdom.

J Thorac Cardiovasc Surg 1999;118:394-403

Copyright (C) 1999 by Mosby, Inc.

$0022-5223 / 99 \$ 8.00+0 \quad \mathbf{1 2 / 6 / 1 0 0 0 7 9}$ diagnosis offered a generous, if inexact, range of possibilities. In fact, the patient had a large atrial septal defect, necessitating 26 minutes of full cardiopulmonary bypass (CPB) support for successful closure.

John Gibbon's “some day" of 1948 became a reality in 1953. But what of the phrase, "a practical affair?" Is that what CPB (the technology of the heart-lung machine and the practice of perfusion) has become? There is something intriguing about the phrase, "a practical affair." The term "affair" conjures up many things in the mind, but permanence is not one of them. In relationships, it suggests that, however bright, however exciting at the start, it will not last.

In this lecture, I wish to develop the argument that, as cardiac surgeons, we need to reconsider our involvement in the technology and the practice of CPB. Rather than viewing $\mathrm{CPB}$ as a historical development, one in which problems have been solved, challenges met, and safe techniques established-yesterday's news - I wish to suggest that we need to reengage our minds and efforts. In short, for cardiac surgeons, CPB cannot afford to be just "a practical affair." It has to be "a committed relationship." If some of you are thinking that there is no case to answer, let me develop my hypothesis and set out the case to be answered.

Cardiac surgeons have failed to maintain their involvement with and understanding of CPB. This lack of involvement (both practical and intellectual) has led to unfamiliarity, progressive lack of understanding, and nonparticipation. For many cardiac surgeons, perfusion has become almost a "no-go area."

Compare the pioneers of the 1950s and 1960s with the surgeons of today. Could your trainees put together a CPB circuit? Could they run a perfusion? In our training programs there is a paucity of teaching in CPB practice and technology. We are creating a new generation of cardiac surgeons unfamiliar with $\mathrm{CPB}$.

I believe that we have abrogated our responsibility in relation to $\mathrm{CPB}$. Since the pioneer phase, we have focused almost exclusively on the developments of surgical technique. You may be saying that our responsibility does not extend to the extracorporeal circuit. That is the perfusionists' area. They are the experts. Indeed 
they are. However, in 1980 a position statement on cardiovascular perfusion was issued by the councils of The American Association for Thoracic Surgery (AATS) and The Society of Thoracic Surgeons (STS). The final paragraph, published in The Journal of Thoracic and Cardiovascular Surgery in February 1980, contained this statement concerning responsibility:

The American Association for Thoracic Surgery and the Society of Thoracic Surgeons firmly believe that the ultimate responsibility for the conduct of a surgical procedure requiring cardiopulmonary bypass resides with the physician/surgeon-in-charge. We also recognize the responsibility of other involved physicians and allied health personnel in conducting such a procedure. However, it must be understood that the surgeon in charge is morally, legally, and ethically responsible for the care of the patient.*

I was amused to note that, 6 months later, the Journal published a small but intriguing correction. It said, in relation to the statement, "the last sentence should read as follows: 'However, it must be understood that the surgeon in charge is morally and ethically responsible for the care of the patient." "1 Morals and ethics are one thing. Clearly, legal implications are something else!

The concept of the surgeon's ultimate responsibility for the conduct of a surgical procedure requiring CPB was restated by the AATS/STS in 1983 and again in 1986.

Acceptance of responsibility is an important part in establishing any committed relationship, but it is certainly not the only part, or even the most important. In any successful relationship, the driving forces must be both positive and stimulating. Looking back in complacency is not enough, however successful the past has apparently been.

In relation to the cardiac surgeon/CPB relationship, I want to consider with you two important topics: (1) the fact that there is still a lot to learn and (2) the need to practice the team approach.

Accounts of the early days of cardiac surgery make for exciting reading - tremendous effort, high drama, elation, and despair. In Gibbon's own story, not only was there the high point of May 6, 1953, there were three other days, one in February 1952 and two in July 1953, when the patients (baby girls aged 15 months, 51/2 years, and $5 \frac{1}{2}$ years, respectively) did not survive, leading to a self-imposed moratorium on cardiac surgery with $\mathrm{CPB}$. In the United Kingdom, the Hammersmith team (Cleland, Bentall, and Dennis Melrose, who

*From Statement on Extracorporeal Technology. J Thorac Cardiovasc Surg 1980;79:316. developed the UK heart-lung machine) would place a rose on the CPB console for every case, and every child having a successful operation was allowed to choose a rabbit from the animal house to take home as a pet.

In those early days, the challenges to be faced daily were monumental. Nowadays, it seems so different. Safety and reliability are never in doubt. Technology is sophisticated, yet relatively inexpensive, and mortality is a mere fraction of that in the 1950s. Yet there is still a lot to learn. If we think that CPB is now "as good as it gets," we delude ourselves. If we think all the big questions have been answered, we are wrong. Although CPB is less traumatic now than in the early days, it remains far from being physiologic. It has its own unique pathophysiology that continues to contribute to the morbidity and even mortality of cardiac surgery procedures. I believe the challenges for research and development are just as great as they were 50 years ago.

Let me illustrate by giving some examples from three important areas of CPB pathophysiology: (1) adequacy of blood flow delivery to organs and tissues; (2) gas exchange and acid-base balance; and (3) blood cell activation, inflammation, and hemostasis.

Just to make the point that there is still a lot to learn, I am going to focus on only one organ potentially affected by these processes during $\mathrm{CPB}$ - the brain. We do not have time to consider other vital organs affected by this pathophysiology, such as the lungs, kidneys, gastrointestinal tract, liver, and the heart itself.

Cardiac surgeons are interested in the brain. Certainly, the fact that the brain is damaged to some extent during cardiac surgery with CPB has been known since the earliest days. In 1954, the year that Gibbon published his article, another article reported the occurrence of brain injury in patients undergoing surgery with $\mathrm{CPB}$. As a profession, we have had 45 years to solve this problem. How much progress have we made?

\section{Blood flow delivery}

The first point to consider is blood flow delivery. What do we know about cerebral blood flow (CBF) during CPB? What are the normal patterns of CBF? What happens to $\mathrm{CBF}$ during cardiac surgery? Is any fall in CBF during CPB sufficient to cause brain damage? Are there subgroups of patients at high risk for brain injury during $\mathrm{CPB}$ ?

We know that $\mathrm{CBF}$ is an autoregulated system (Fig 1) in which flow is maintained across a wide range of perfusion pressures (approximate range of mean systemic blood pressures, $50-150 \mathrm{~mm} \mathrm{Hg}$ ). Above and below these limits, $\mathrm{CBF}$ becomes pressure passive. The autoregulation of $\mathrm{CBF}$ is a nice example of the homeo- 


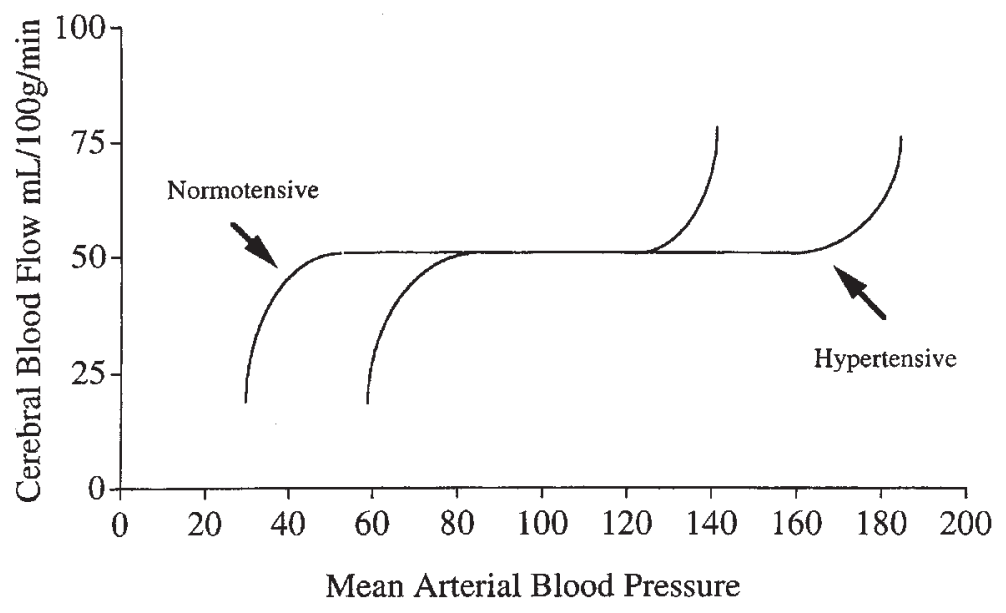

Fig 1. Autoregulation of cerebral blood flow for normotensive and hypertensive patients.

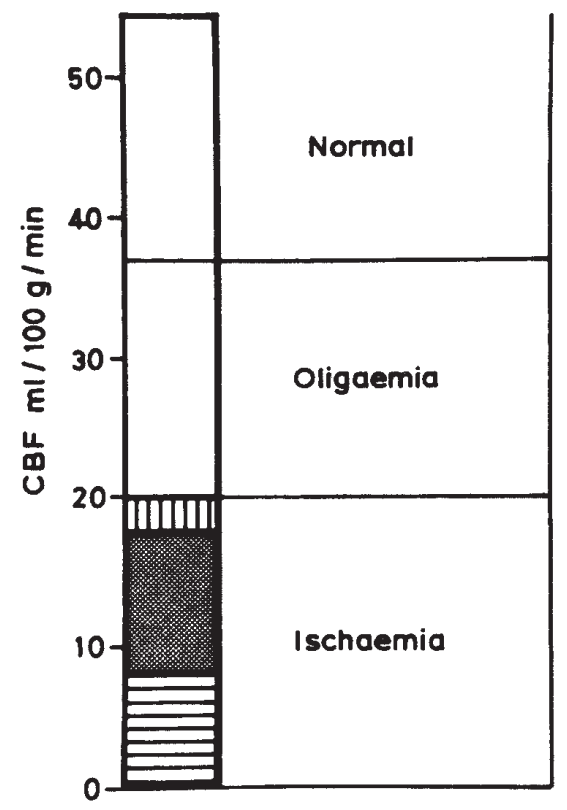

Fig 2. Cerebral ischemic thresholds. $C B F$, Cerebral blood flow.

static plateau concept of Claude Bernard: the "milieu interior," "the constancy of the internal environment is the necessary condition for the free life." This autoregulated system is reassuring, but what happens to $\mathrm{CBF}$ during cardiac surgery?

Investigators have reported that $\mathrm{CBF}$ falls to a variable extent (range $20+\mathrm{mL} \cdot 100 \mathrm{~g}^{-1} \cdot \mathrm{min}^{-1}$ ) during $\mathrm{CPB}$ and then returns to near normal levels in the post$\mathrm{CPB}$ period. We should note that $\mathrm{CBF}$ levels may be influenced by various factors, notably temperature and arterial $\mathrm{PCO}_{2}$ levels. We should also be aware that autoregulation of CBF may itself be lost under certain circumstances, notably with deep hypothermia $\left(15^{\circ} \mathrm{C}\right.$ $20^{\circ} \mathrm{C}$ ) and with $\mathrm{pH}$-stat acid-base management.

However, the key question is surely this: If CBF can fall during CPB to 20 to $25 \mathrm{~mL} \cdot 100 \mathrm{~g}^{-1} \cdot \mathrm{min}^{-1}$, is this fall sufficient to cause brain cell damage? This question is answered by Astrup's concept of brain ischemic thresholds. He and his colleagues ${ }^{2}$ reported in 1977 that $\mathrm{CBF}$ had to fall below $10 \mathrm{~mL} \cdot 100 \mathrm{~g}^{-1} \cdot \mathrm{min}^{-1}$ for ischemic cell death to occur, and this threshold was established at normothermia; hypothermia afforded increased protection (Fig 2).

These data challenge the often-stated belief that the brain is very sensitive to reduced global perfusion. In fact, the brain appears relatively resistant to reduced $\mathrm{CBF}$ and to reduced systemic blood pressure.

However, I am not advocating complacency. There are identifiable groups of patients at increased risk of brain injury during cardiac surgery. These include elderly patients, hypertensive patients, patients with flow-limiting cerebrovascular stenoses, and patients with a previous cerebrovascular accident.

Alterations to the $\mathrm{CBF}$-autoregulated plateau may be the explanation for the increased risk in some of these groups. Certainly, the CBF lower limit of autoregulation is higher in patients with chronic hypertension. The whole curve shifts to the right. In elderly patients, it is not unreasonable to suggest that, with increased age, the width of the autoregulatory plateau may be progressively reduced, but I am not aware of any research on this topic.

\section{Gas exchange and acid-base protocols during CPB}

I shall now consider how gas exchange and acid-base management during CPB might affect the brain. For 

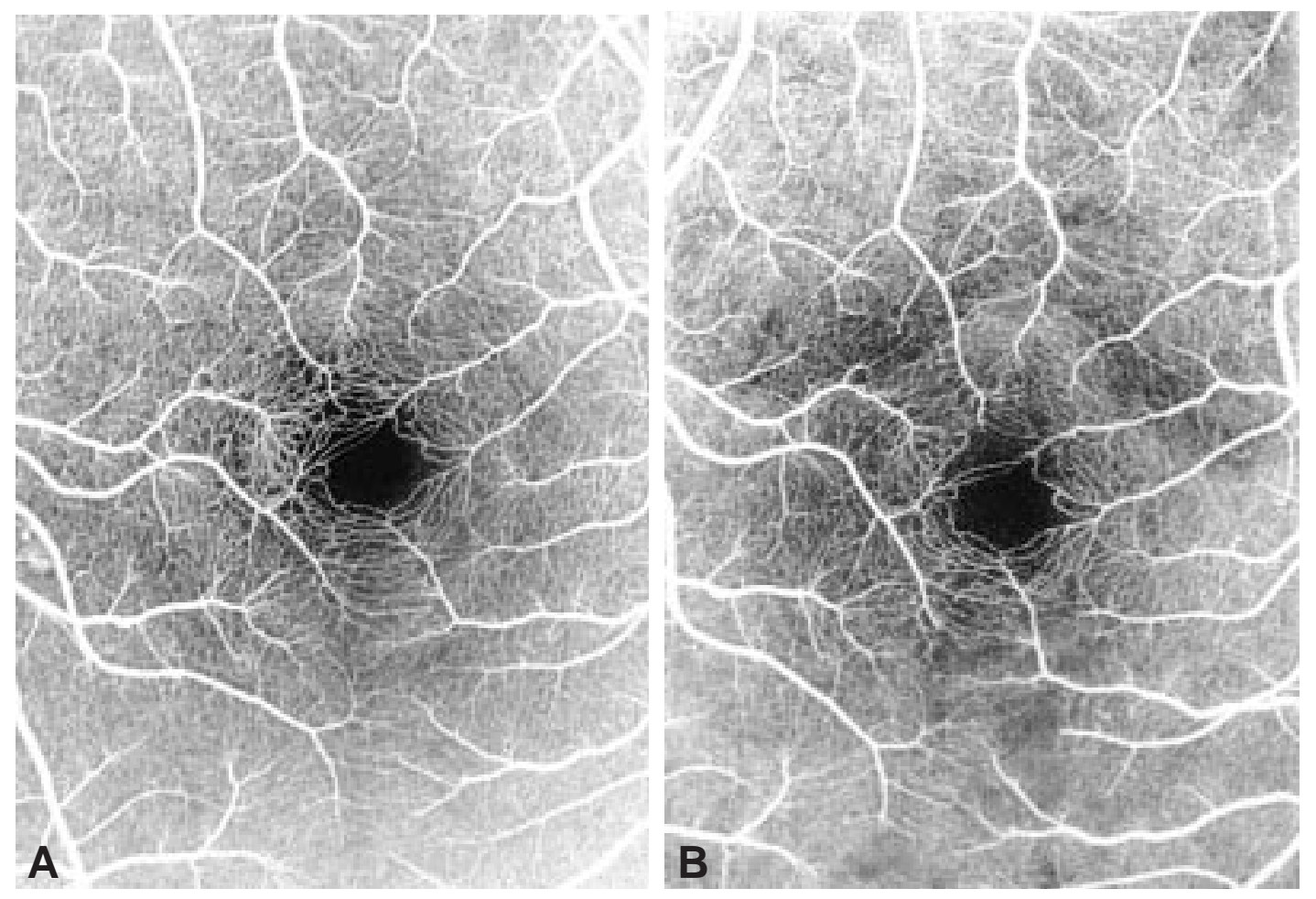

Fig 3. Retinal fluorescein angiograms obtained from a patient undergoing coronary bypass graft surgery. A, Angiogram obtained 5 minutes before onset of CPB. B, Angiogram obtained after 60 minutes of CPB. Note truncation of vessels and loss of blood vessel filling in angiogram $\mathbf{B}$ in the segment between the 10-o'clock and 1o'clock positions on the macula (central dark object).

many years, the only gas really worth bothering about during cardiac surgery was oxygen. Although the pioneers used the term artificial lung to describe that component of the CPB circuit, the term oxygenator soon replaced it. This change was more than mere semantics, for the lung does more than oxygenate: (1) gas exchange is not equivalent to oxygenation and (2) gas exchange involves the introduction of oxygen plus the removal of carbon dioxide.

Preoccupation with oxygenation may lead to a number of unfortunate consequences:

- The mistaken belief that, if the arterial return blood from the CPB circuit is bright red, then all is well with the world. (The brighter the better!)

- Failure to recognize that gaseous microbubbles and gaseous microembolism are generated in direct proportion to the arterial $\mathrm{PO}_{2}$ level

- Failure to be aware of the importance of control of arterial $\mathrm{PCO}_{2}$ in relation to $\mathrm{CBF}$ and cerebral microembolism

Looking first at cerebral microembolism, the elegant studies carried out by Blauth and associates ${ }^{3}$ used fluorescein retinal angiography to image the retinal circula- tion during cardiac surgery. The eye develops embryologically as an outgrowth from the brain, taking its blood supply directly from the cerebral circulation. Retinal angiography, therefore, provides a unique window on the events occurring in the cerebral circulation. In their early studies (Fig 3, $A$ and $B$ ), Blauth and Arnold showed diffuse occlusions in retinal arterioles during $\mathrm{CPB}$, with consequent loss of perfusion to areas of the retina. They used computerized image analysis to quantify the ischemic areas produced.

In subsequent studies, they compared bubble oxygenators and membrane oxygenators and found a substantial reduction in retinal defects in the membrane oxygenator group. The incidence of defects was reduced from $100 \%$ in the bubble oxygenator group to under $50 \%$ in the membrane group. The great advantage of membrane oxygenation relates to the ability to control oxygen and carbon dioxide independently, thus avoiding the over-oxygenation produced by high-efficiency bubble oxygenators, particularly in the rewarming phase of CPB. However, this 50\% improvement, welcome though it was, has not to my knowledge progressed any further. 


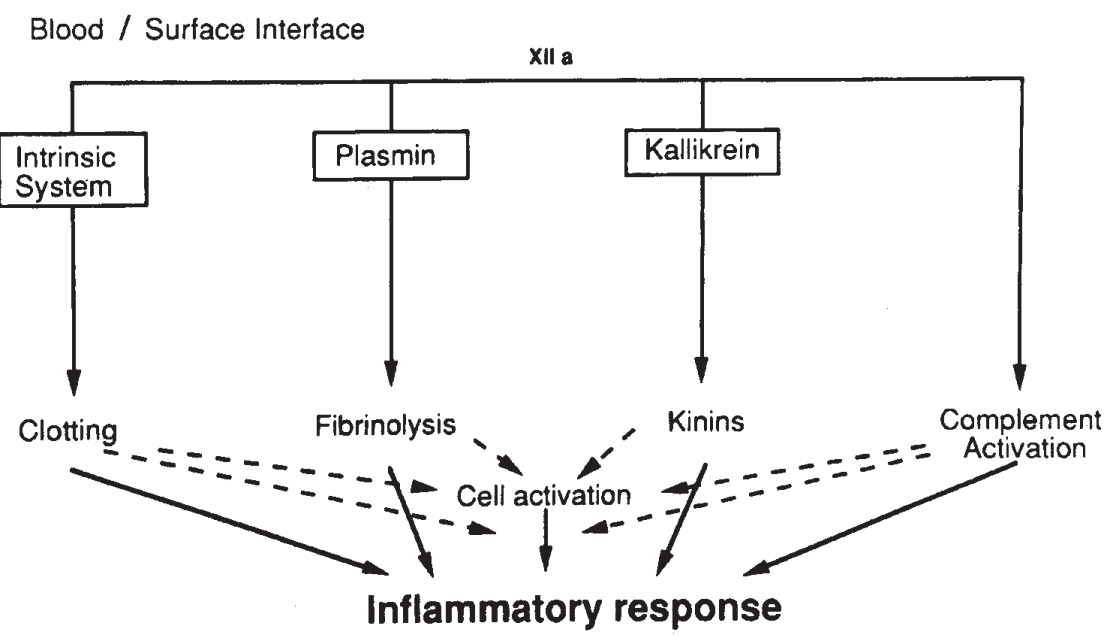

Fig 4. Contact activation flow diagram.

Turning now to acid-base management during hypothermic $\mathrm{CPB}$, we come face to face with the alpha-stat/pH-stat question. I have come to the conclusion that this topic is not so much controversial as confusing. In the basic science part of the United Kingdom's cardiothoracic surgical specialty fellowship examination, I often ask the candidates, "Which stat protocol do you use in your unit?" Invariably, the answer comes quickly and confidently: "Alpha/pH." Right then, I say, "Tell me the difference between these strategies." This is usually where it all comes unstuck, particularly if the candidate tries to explain what the alpha of alpha-stat stands for. It is the perfect excuse to hand out BAIK badges-Boy Am I K(c)onfused.

The essential difference in these two approaches relates to what happens to carbon dioxide. As core temperature is reduced, carbon dioxide going into solution increases, $\mathrm{PCO}_{2}$ falls, and $\mathrm{pH}$ rises. With alpha-stat management, no intervention is undertaken. With $\mathrm{pH}$ stat management, sufficient additional carbon dioxide is introduced via the oxygenator to maintain the $\mathrm{pH}$ at physiologic normothermic levels.

With the pH-stat strategy, therefore, total carbon dioxide content is increased. "So what?" you say. As far as the brain is concerned, $\mathrm{pH}$-stat management has a number of consequences:

- Autoregulation of CBF is impaired or even lost completely

- $\mathrm{CBF}$ is relatively increased by the increase in $\mathrm{PCO}_{2}$ compared with alpha-stat levels

- The ratio of $\mathrm{CBF}$ to cerebral metabolic needs is altered

The significance of the changes in flow/metabolism ratios needs further discussion. $\mathrm{CBF} /$ metabolism ratio expresses the adequacy of CBF in supplying the necessary amounts of energy substrate to meet cerebral metabolism, conventionally expressed as the cerebral metabolic rate for oxygen $\left(\mathrm{CMRO}_{2}\right)$. At normothermia, $\mathrm{CBF}$ is around $40 \mathrm{~mL} \cdot 100 \mathrm{~g}^{-1} \cdot \mathrm{min}^{-1}$ and $\mathrm{CMRO}_{2}$ is around 2.5 to $3 \mathrm{~mL} \cdot 100 \mathrm{~g}^{-1} \cdot \mathrm{min}^{-1}$. The ratio of flow to metabolism is therefore around 15:1.

See what happens to $\mathrm{CBF}$ and $\mathrm{CMRO}_{2}$ with progressive cooling: $\mathrm{CBF}$ reduces linearly with reducing temperature, whereas $\mathrm{CMRO}_{2}$ reduces exponentially. At $28^{\circ} \mathrm{C}$, therefore, the flow/metabolism ratios are significantly altered, and the choice of alpha-stat or $\mathrm{pH}$-stat management also affects the ratios. At $28^{\circ} \mathrm{C}$ with alpha-stat management the ratio increases to $30: 1$, but with $\mathrm{pH}$-stat management the ratio increases to 60:1.

One might think superficially that this must be good, with a mighty excess of CBF over the metabolic needs of the brain. However, this degree of "luxury perfusion" is at best unnecessary and at worst deleterious, increasing the embolic load delivered to the brain (both gaseous and particulate).

Historically, in the 1960s and 1970s, the standard acid-base protocol in CPB was $\mathrm{pH}$-stat. The physiologic basis for alpha-stat management began to emerge in the mid to late 1980s. However, to reiterate the point that we still have a lot to learn, the argument has moved again in the mid 1990s, with studies from Richard Jonas and colleagues that suggest that the $\mathrm{pH}$-stat strategy may be associated with improved cerebral outcomes, at least in pediatric practice. It is all very confusing.

\section{Blood cell activation, inflammation, and hemostasis}

If our understanding of the issues of blood flow delivery and gas exchange/acid-base balance has pro- 


\title{
The endothelial cell-leukocyte adhesion cascade
}

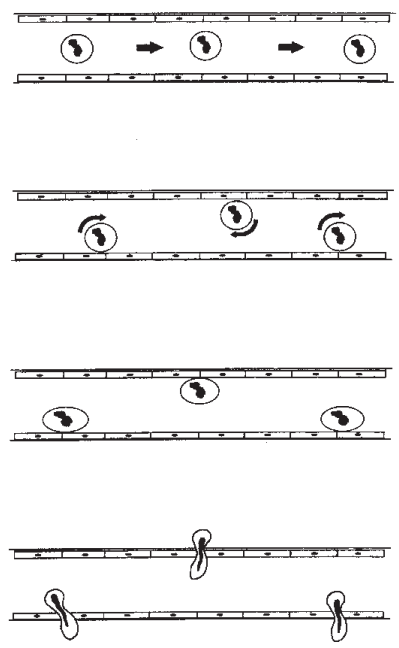

\author{
Baseline
}

Rolling (Selectins)

Firm adhesions (Integrins)

Fig 5. Leukocyte/endothelial interaction steps in the process of inflammation.

gressed somewhat from Gibbon's day, albeit with more unanswered questions now than when it all began, in the area of blood cell activation we have scarcely scratched the surface. CPB imposes unphysiologic contact between the patient's blood and the surfaces of the extracorporeal circuit. The term contact activation has been used to describe the complex series of cascades involving the coagulation, fibrinolytic, kallikrein, and complement systems (Fig 4), leading ultimately to activation of white blood cells and platelets with the generation of a systemic inflammatory response syndrome (SIRS). ${ }^{4}$

The inflammatory response is one of the most fundamental protective responses we possess, but it functions as a local response, focusing the body's defenses at the point of injury. The problem in cardiac surgery is that the response becomes systemic, potentially distributed throughout the body, affecting all vital organs and tissues.

The new disciplines of molecular biology and genetic science have allowed us to begin to characterize those events that establish the inflammatory response, particularly the interactions between leukocytes and vascular endothelium. ${ }^{5}$

The sequence of events causing inactive leukocytes to move from free flow in the circulating blood and become activated and localized in tissues, producing inflammation, is thought to be as follows (Fig 5):

- Rolling of leukocytes along the endothelium is mediated by adhesion molecules called selectins

- The rolling movement progresses to firm attachment of the leukocyte to endothelium, mediated by integrins
- Finally, the adherent, activated leukocyte moves through the endothelial layer into the extravascular tissue, a process known as transmigration, also mediated by integrins

This is a concise, simplified view of inflammation. But is this what happens in patients undergoing cardiac surgery? These are the questions we need to ask: Is CPB a stimulus to the development of SIRS? Is it an inevitable consequence of CPB? Is the pattern of SIRS in cardiac surgery the same as or different from the response in other disease states?

We honestly do not know the answers to these vital questions as yet. Research in this area is progressing rapidly. It is interesting, however, to mention some work my own department published in the mid 1980s, when we were trying to characterize the effects of $\mathrm{CPB}$ on leukocyte trapping in the lung 6 (Fig 6, A, B, and $C$ ).

- Before CPB, the leukocyte lies free in the pulmonary capillary

- Thirty minutes after CPB, the leukocyte has become attached to the pulmonary capillary endothelium (firm adhesion)

- Two hours after CPB, the leukocyte is growing footlike processes (pseudopodia) and is moving through the endothelium into the extravascular space (transmigration)

Do these effects relate to the brain as well as the lung? We think they may. In 1993 we carried out a pilot study of immediate postoperative brain imaging using magnetic resonance imaging (MRI) in six patients undergoing coronary surgery. ${ }^{7}$ When I say immediate, I mean immediate. The patients were transferred from 

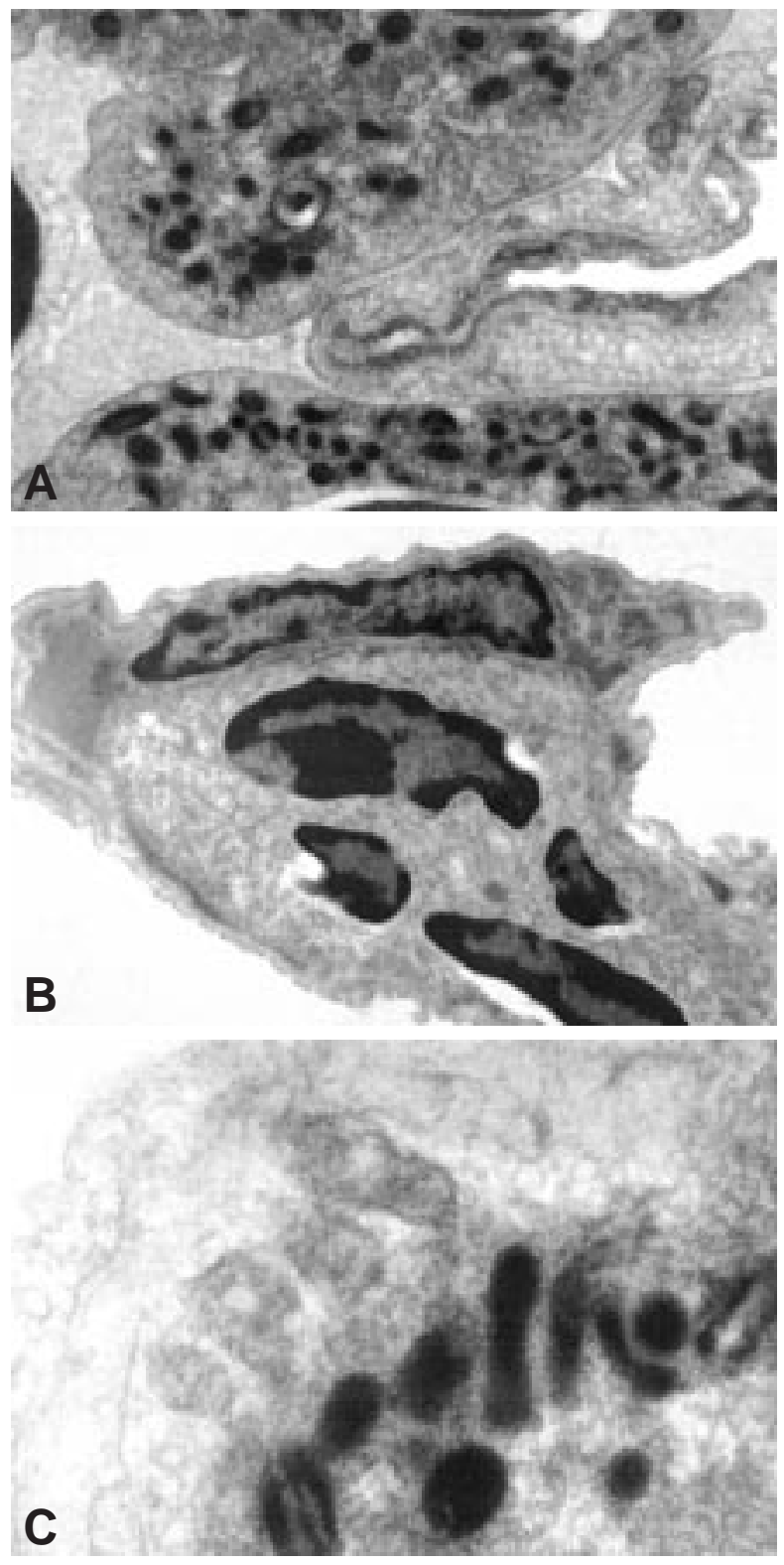

Fig 6. Leukocyte/endothelial cell interaction in a pulmonary capillary. Scanning electron microscope images of lung biopsy specimens obtained. A, Before CPB; B, 30 minutes after CPB; $\mathbf{C}, 120$ minutes after CPB.

the operating theater to the MRI suite with the images being obtained within 60 minutes of the end of the operation. Each patient had optimal 1990s CPB with moderate hypothermia, alpha-stat acid-base management, pulsatile perfusion, arterial filtration, and membrane oxygenators. None of the preoperative MRIs showed abnormalities, and in all six patients the immediate postoperative image revealed acute brain swelling
(Fig 7, $A$ and $B$ ). The swelling was not present 24 hours after the operation. These observations represent an acute perioperative situation. All six patients had a rapid, uneventful postoperative recovery, specifically with no central nervous system complications.

These findings challenged our complacency. Even with the optimal cerebral protective measures known to date, our current practice leads to this structural change in the brain.

We have just completed a major follow-up study to investigate further this phenomenon and assess whether therapy designed to modify the SIRS might prevent, or at least reduce, this acute brain swelling. This prospective, randomized, placebo-controlled, double-blind study in patients undergoing coronary artery bypass grafting involved the following:

- Brain MRI: less than 24 hours before the operation, immediately after the operation, and 12 months after the operation

- Neuropsychologic assessment: before the operation and 8 days, 8 weeks, and 12 months after the operation

- SIRS markers: leukocyte profiles, adhesion molecules (selectins, integrins), and inflammatory cytokines

The therapeutic agent in the study is aprotinin, the protease inhibitor drug with potentially widespread inhibition of several of the inflammatory cascades. The results of the study will not be known for some time, until the drug/placebo codes are broken. However, we do know that we have (1) patients in whom MRIs in the immediate postoperative period show no abnormalities and (2) patients with marked inhibition of the patterns of leukocyte activation and inflammation.

I have spent a good deal of time on the topic, "We've still got a lot to learn." I now want to deal more briefly with my second positive point regarding committed relationships: the need to practice the team approach. The idea is that the partners in the relationship bring complementary attributes.

You need only walk into a cardiac surgery operating room to understand that a cardiac operation involves a large team of people. I used the term "operating room" advisedly. In the United Kingdom, we use the term "operating theater." I have often thought that the preference for "theater" reinforces the perception that surgeons in general, and cardiac surgeons in particular, are true prima donnas.

You may have begun to think, "I detect some inconsistency creeping in. Earlier you were saying, 'The surgeon carries ultimate responsibility.' Now you are saying, 'It is a team effort.' Surely you cannot have it both ways."

I do believe that the surgeon should continue to carry 

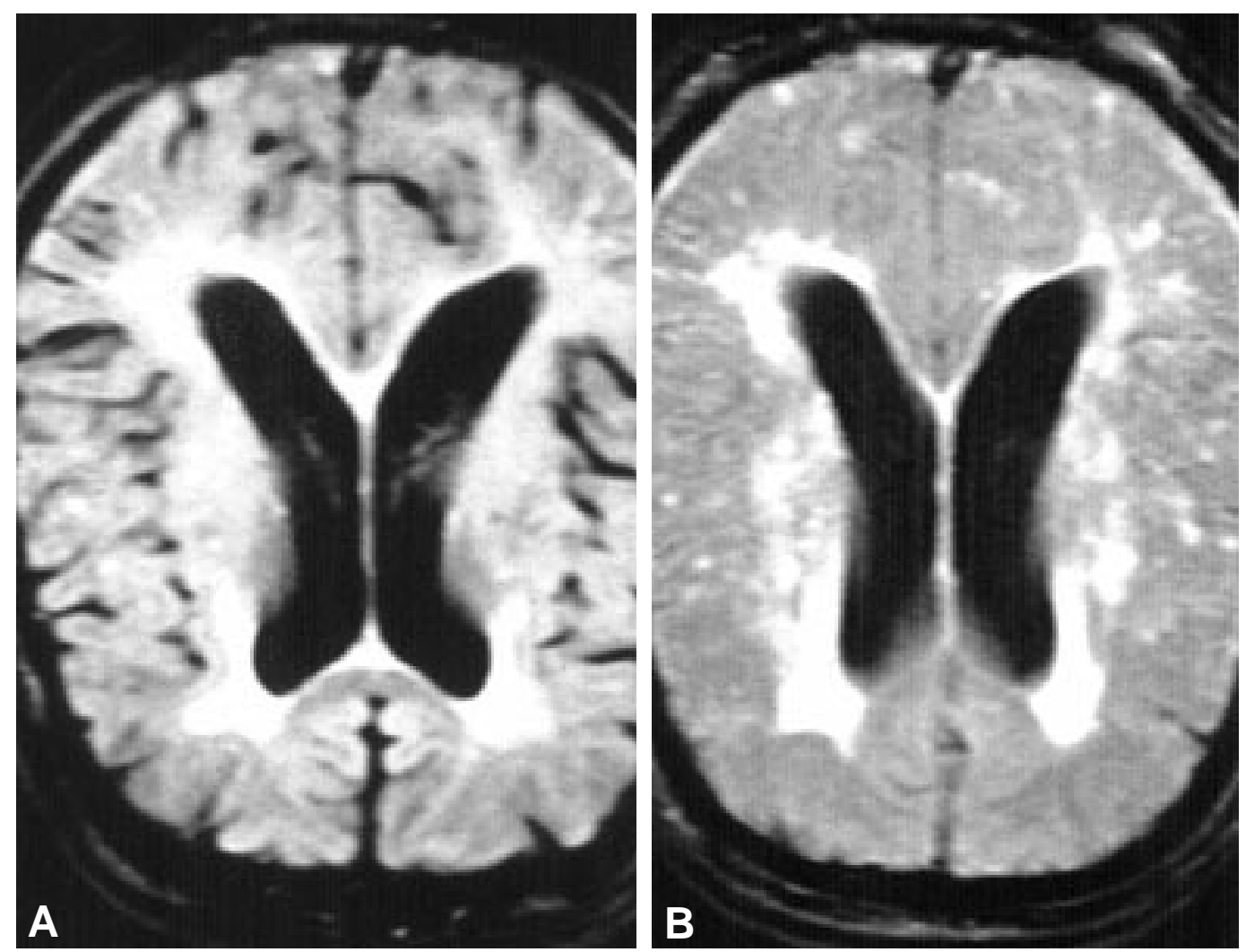

Fig 7. Magnetic resonance images of the brain of a patient undergoing coronary bypass surgery. A, Image obtained 24 hours before the operation. B, Image obtained 60 minutes after the coronary bypass operation.

ultimate responsibility, but as for any captain (of a team, of a ship, or of an aircraft), that responsibility is accepted in the context of a collaborative effort. This has to be true for the cardiac surgical team in general and, to be specific to my subject, for the relationship between cardiac surgeons and the technology and practice of CPB.

I want to consider two other partners in this relationship: the perfusionist and industry. I hope to convince you all that the right involvement of surgeons, in collaboration with perfusionists and industry, will promote progress, with added value for all concerned.

\section{Development of perfusionists—professional and educational}

In the early days of cardiac surgery, the role of the perfusionist was, to say the least, somewhat arbitrary. On-the-job training was the order of the day, with little or no formal training or structured syllabus. This was hardly surprising, given that these were pioneering days.

Formal perfusionist training programs began to appear in the 1970 s, initially driven by the manpower require- ments in the larger units. In 1973, in the United States, programs existed only at The Cleveland Clinic, Pittsburgh Shadyside, and the Texas Heart Institute. Board certification of perfusionists was introduced in 1975, with the establishment of the American Board of Cardiovascular Perfusion. Establishment of the Board was not without incident, and tensions between the perfusionists and cardiac surgeons were evident in the late 1970s and early 1980s, although they have been resolved.

The support of the AATS and STS for perfusionists' formal training and continued professional development was made clear in the 1980s when the Coordinating Committee on Perfusion Affairs was established under the wise leadership of Gerald Rainer.

On the other side of the Atlantic, the process was similar. Various national perfusionist societies were established in the 1960s and 1970s. Some moved rapidly to formal training and certification (eg, the Dutch Society, NeSECC). In the United Kingdom, the level of perfusionist education was further advanced in 1983 when the United Kingdom School of Perfusion Sciences was established-fully supported by the 
United Kingdom Societies of Cardiothoracic Surgeons and Cardiothoracic Anaesthetists - and the Society of Perfusionists. The School of Perfusion Sciences established a two-year postgraduate diploma in perfusion science and now offers an additional master of science degree in perfusion science. In 1991, the European Board of Cardiovascular Perfusion was established, again with the full support of the European Association for Cardiothoracic Surgery (EACTS), the European Society of Cardiovascular Surgery, and the European Association of Cardiothoracic Anaesthesiologists. The current chairman of the European Board of Cardiovascular Perfusion is a cardiac surgeon, Ludwig von Segesser, from Lausanne, Switzerland.

These steps in professional development of perfusionists have been paralleled by steady progress in academic activities. The two principal North American societies, the American Society for Extra-Corporeal Technology (AMSECT) and the American Academy for Cardiovascular Perfusion, have published their respective journals/proceedings for several years. In 1986, the first issue of Perfusion, the international specialty journal for $\mathrm{CPB}$, was published. The journal is now in its thirteenth year of publication, fully cited in the Cumulated Index Medicus, and with particularly close links with international perfusion societies (American Academy for Cardiovascular Perfusion, European Board, and Australasian Society of Perfusion).

I have been particularly gratified, over the 13 years of publishing Perfusion, to see the steady increase in the quantity, and especially the scientific quality, of manuscripts received from the perfusion community. Experience with the peer review process has been uniformly beneficial.

I believe that the emergence of perfusion as a profession allied to medicine is a wholly positive development. The AATS/STS statement on perfusionist affairs in 1982 set the pattern: "Encourages and supports the efforts of the organized bodies of extracorporeal technologists to improve the quality of education for perfusionists and promote research and continuing education to insure high standards of practice and safety of patients undergoing extracorporeal circulation."

I believe that, to a considerable extent, these laudable objectives have been achieved. The team effort in cardiac surgery has benefited enormously from the professional development of perfusionists. They now represent a real technologic and research resource, and we cardiac surgeons should, must, engage with them. But the initiative must come from the cardiac surgeons, because the fundamental issue of responsibility has not changed. It remains, in my view, as it was restated by
Richard Clark and George Magovern ${ }^{9}$ in a 1982 editorial in The Journal of Thoracic and Cardiovascular Surgery: "The further success of the profession of cardiovascular perfusion depends clearly upon continued recognition by cardiac surgeons as well as perfusionists that the conduct of cardiac surgery and cardiopulmonary bypass is properly the ultimate responsibility of the cardiac surgeon."

\section{The team approach as it applies to industry}

I do not know what your approach is to representatives of manufacturing or pharmaceutical companies. I suspect, however, that many cardiac surgeons are increasingly reluctant to meet and discuss issues/new products in the area of perfusion. If my original hypothesis is correct, why should we get into situations in which our relative unfamiliarity with and ignorance of perfusion matters may become only too obvious? If that assessment is unfair, I apologize, but my perception is that industry may have more access to and discussions with the perfusionist than with the cardiac surgeon. If cardiac surgeon/industry communication is not occurring, then both sides lose. Cardiac surgeons lose out on new thinking and new possibilities in technology or pharmacology, and industry loses out on the clinician's real grasp of clinical reality. The one who picks up the final bill is the patient.

The clinical reality issue is very important. Over the years, a number of giant leaps in perfusion technology have been hailed by industry and variably accepted into perfusion practice. I believe some are spurious in concept and impotent in practice. Here are some of my personal bêtes noires:

- "Physiologic" or, as we prefer to say, "physiological"

- "State of the art" technology. What does that mean, other than that it was introduced today as opposed to yesterday?

- Low priming volume components, when we are not able to prevent the vascular permeability changes of the SIRS

- Heparin-coated circuits and biocompatibility. I accept that surface modification of CPB circuits is conceptually attractive, but heparin is not the optimal substance

These are only a few examples, but to substantiate my prejudices, here are direct quotes from 10 arbitrarily selected, consecutive ads in a recent cardiac surgery journal:

- "State of the art"-mentioned three times

- "Physiologic"-mentioned three times

- "Low priming volume"-mentioned twice

- "Biocompatibility"-mentioned twice 
I am certainly not trying to be offensive. Rather, I feel very strongly that great opportunities are being missed: opportunities for a two-way education process between cardiac surgeons and industrial research and development; opportunities and responsibilities of cardiac surgeons to reengage in selection of perfusion equipment and technology; and combined involvement of clinicians and industry in the education process, particularly in the introduction of new concepts and new technologies.

\section{Summary}

There we have it. I have rehearsed my original argument that, for us as cardiac surgeons, the technology and practice of CPB cannot just be a practical affair. It has to be a committed relationship driven by our current ignorance (there is still a lot to learn) and characterized by the team approach (while the surgeon retains ultimate responsibility). Some specific challenges are obvious:

- CPB in pediatric practice. Listen to these words:

We believe that the quality of $\mathrm{CPB}$ practiced upon children must improve and continue to improve.

We hope that we will be able to stimulate some among you to take up arms in the fight against the morbidity it [CPB] can produce.

Many of the technical battles in [adult] cardiac surgery have been won, but, for CPB in children, we the combatants have barely entered the field. ${ }^{10}$

The preceding statements were not written in the early days of CPB, but as recently as $1994 .{ }^{10}$

- Brain protection, when, with the best of current knowledge and practice, this is the picture immediately after apparently straightforward, successful coronary surgery

- The new technologies and practice of less invasive $\mathrm{CPB}$ and the extended role of $\mathrm{CPB}$
I began with John Gibbon, prophetic in 1948, reality in 1953. But I discovered that Dr Samuel Johnson was well ahead of his time. In the 1700s he knew about SIRS. "SIRS," he said, "I have found you an argument, I am not obliged to find you an understanding." 11 In this area of cardiac surgical practice, he may not have felt obliged to find an understanding, but we must. That is the challenge - to reengage in CPB and see it as integral to our profession and practice as cardiac surgeons, not a practical affair, but a committed relationship.

\section{REFERENCES}

1. Notice of correction: Statement on extracorporeal technology. J Thorac Cardiovasc Surg 1980;80:313.

2. Astrup J, Symon L, Branston MN, et al. Cortical evoked potential and intracellular $\mathrm{K}^{+}$and $\mathrm{H}^{+}$at critical levels of brain ischemia. Stroke 1977;8:51-8.

3. Blauth C, Arnold J, Kohner EM, Taylor KM. Retinal microembolism during cardiopulmonary bypass demonstrated by fluorescein angiography. Lancet 1986;2:837-9.

4. American College of Chest Physicians/Society of Critical Care Medicine Consensus Conference. Definitions for sepsis and organ failure and guidelines for the use of innovative therapies in sepsis. Crit Care Med 1992;20:864-8.

5. Asimakopoulos G, Taylor KM. Effects of cardiopulmonary bypass on leukocyte and endothelial adhesion molecules. Ann Thorac Surg 1998;66:2135-44.

6. Royston D. Blood cell activation. Semin Thorac Cardiovasc Surg 1990;2:341-57.

7. Harris DNF, Bailey SM, Smith PLC, et al. Brain swelling in the first hour after coronary artery bypass surgery. Lancet 1993;342: 586-7.

8. Proposed statement on perfusionist affairs. J Thorac Cardiovasc Surg 1982;84:636.

9. Clark RE, Magovern JG. Training and certification of cardiovascular perfusionists. J Thorac Cardiovasc Surg 1982;83:324-5.

10. Jonas RA, Elliot ME. Preface. In: Jonas RA, Elliot ME, editors. Cardiopulmonary bypass in neonates, infants and young children. Oxford: Butterworth Heineman; 1994.

11. Johnson S. In: Boswell's life of Johnson. June 1784. 